\title{
Effects of chronic alcohol exposure on ischemia- reperfusion-induced acute kidney injury in mice: the role of $\beta$-arrestin 2 and glycogen synthase kinase 3
}

\author{
Lihua Wang ${ }^{1}$, Yifei Zhu ${ }^{2}$, Lili Wang ${ }^{1}$, Jingjing $\mathrm{Hou}^{1}$, Yongning Gao ${ }^{1}$, Lei Shen ${ }^{1}$ and Jingyu Zhang ${ }^{3}$
}

Little is known about the effects of chronic alcohol intake on the outcome of acute kidney injury (AKI). Hence, we examined the effects of chronic alcohol intake on the development of renal fibrosis following AKI in an animal model of bilateral renal ischemia-reperfusion (IR) injury. We first found that chronic alcohol exposure exacerbated bilateral IR-induced renal fibrosis and renal function impairment. This phenomenon was associated with increased bilateral IR-induced extracellular matrix deposition and an increased myofibroblast population as well as increased bilateral IR-induced expression of fibrosis-related genes in the kidneys. To explore the mechanisms underlying this phenomenon, we showed that chronic alcohol exposure enhanced $\beta$-arrestin 2 (Arrb2) expression and Akt and glycogen synthase kinase-3 (GSK3) $\beta$ activation in the kidneys. Importantly, pharmacological GSK3 inhibition alleviated bilateral IR-induced renal fibrosis and renal function impairment. Furthermore, we demonstrated that Arrb2 $^{-/-}$mice exhibited resistance to IR-induced renal fibrosis and renal function impairment following chronic alcohol exposure, and these effects were associated with attenuated GSK3 $\beta$ activation in the kidneys. Taken together, our results suggest that chronic alcohol exposure may potentiate AKI via $\beta$-arrestin 2/Akt/GSK3 $\beta$-mediated signaling in the kidney. Experimental \& Molecular Medicine (2017) 49, e347; doi:10.1038/emm.2017.76; published online 23 June 2017

\section{INTRODUCTION}

Acute kidney injury (AKI) is a major clinical problem that can result in prolonged hospitalization, chronic renal failure and death. ${ }^{1-5}$ One of the leading causes of AKI is renal ischemia-reperfusion injury (IRI) due to surgical renal ischemia or renal hypoperfusion. ${ }^{1,2}$ Importantly, evidence has shown that the severity and incidence of AKI have been increasing in recent years. ${ }^{6}$ Hence, studies are necessary to identify the cellular and molecular mechanisms underlying acute kidney injury in order to provide therapeutic targets for AKI prevention and therapy.

Although the associations between high alcohol consumption and the progression of kidney damage such as chronic kidney disease (CKD) remain controversial, ${ }^{7}$ it has been recognized that chronic alcohol intake can affect renal function. For example, alcoholic liver cirrhosis with associated hepato-renal syndrome is a common complication of chronic alcohol consumption and can result in renal failure because of extreme splanchnic vasodilatation and compensatory renal vasoconstriction. ${ }^{8,9}$ In addition, evidence has suggested that a wide range of disturbances in electrolyte and acid-base balance can be observed in alcoholics because of alcoholinduced tubular dysfunction. ${ }^{10-13}$ Therefore, we hypothesized that a history of chronic alcohol intake may worsen the consequences of AKI.

Renal IRI is a widely used animal model for the study of mechanisms underlying AKI. As a model of AKI, bilateral renal IRI can induce a significant increase in serum creatinine and blood urea nitrogen (BUN), which are also seen in patients with AKI. ${ }^{6,14}$ While some studies have examined the long-term impact of bilateral renal IRI, ${ }^{15-17}$ most have indicated that kidney function and morphology can return to almost normal $\sim 2$ weeks after the initial mild bilateral renal IRI. ${ }^{14,18,19}$ As a result, the consequences of AKI induction are generally

\footnotetext{
${ }^{1}$ Division of Blood Purification, The Second Hospital of Hebei Medical University, Shijiazhuang, China; ${ }^{2}$ Department of Neurology, The Second Hospital of Hebei Medical University, Shijiazhuang, China and ${ }^{3}$ Department of Hematology, The Second Hospital of Hebei Medical University, Key Laboratory of Hematology of Hebei Province, Shijiazhuang, Hebei, China

Correspondence: Dr L Wang, Division of Blood Purification, The Second Hospital of Hebei Medical University, No. 215 Peace Road, Shijiazhuang 050000 , Hebei, China.

E-mail: Ihwwanglihua@sina.com

or Dr J Zhang, Department of Hematology, The Second Hospital of Hebei Medical University, Key Laboratory of Hematology of Hebei Province, No. 215 Hepingxi Road, Hebei, Shijiazhuang 050000, China.

E-mail: zjyhbsjz@163.com

Received 2 November 2016; revised 13 January 2017; accepted 25 January 2017
} 


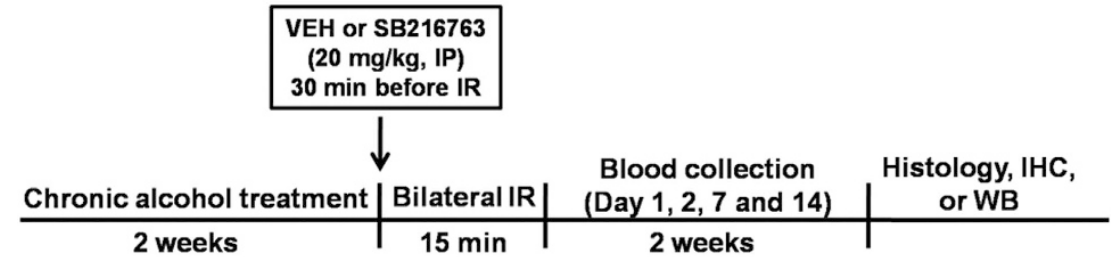

b Arrb2-I-(12 weeks old)

\begin{tabular}{c|c|c|c} 
Chronic alcohol treatment & Bilateral IR & $\begin{array}{c}\text { Blood collection } \\
(\text { Day 1, 2,7 and 14) }\end{array}$ & Histology or WB \\
\hline 2 weeks & $15 \mathrm{~min}$ & 2 weeks &
\end{tabular}

Figure 1 Experimental timeline. Twelve-week-old male $\beta$-arrestin-2 knockout mice and WT C57BL/6J control mice were used for the experiments. The mice were randomly separated into two treatment groups. (a) One group of mice received a dextrose-containing liquid diet, and the second group received a nutritionally complete liquid diet containing $4.5 \%(\mathrm{v} / \mathrm{v})$ ethanol in their home cages for 2 weeks. Renal IRI was conducted by clamping both renal pedicles for $15 \mathrm{~min}$ under pentobarbital anesthesia (60 $\mathrm{mg} \mathrm{kg}^{-1}$, i.p.), followed by reperfusion. (b) Sham groups of mice underwent surgery to expose the renal pedicles without clamping. Tail vein blood samples were collected to measure blood urea nitrogen (BUN) and creatinine levels. Histology, immunohistochemistry and western blot analyses were performed at 14 days post IRI. IRI, ischemia-reperfusion injury.

studied from $24 \mathrm{~h}$ to up to 2 weeks after the bilateral renal IRI. ${ }^{19-22}$ Hence, we used a rodent bilateral renal IRI model in the present study to examine the effects of chronic alcohol intake on the consequences of mild AKI 2 weeks after injury.

One of the classic outcomes of AKI is renal fibrosis, which can develop as a consequence of maladaptive repair after acute kidney injury. ${ }^{23,24}$ Importantly, previous studies have demonstrated that the glycogen synthase kinase-3 (GSK3) family of protein kinases plays a critical role in injury and repair of renal tubular epithelial cells after AKI. Specifically, GSK3 $\beta$ gene knockdown reduces AKI-induced apoptosis in vitro and in vivo. ${ }^{25,26}$ Moreover, pharmacological inhibition of GSK3 reduces apoptosis and renal tubular injury in renal IRI. ${ }^{25-29}$ Furthermore, it has been shown that GSK3 $\beta$ is expressed in renal myofibroblasts, ${ }^{30}$ which are critical for the development of renal fibrosis following renal IRI. In fact, previous studies have shown that GSK3 inhibition can attenuate fibroblast activation and fibrosis development following renal IRI in mice. ${ }^{30}$ Given that previous studies have shown that chronic alcohol exposure results in GSK3 $\beta$ activation in the liver and brain, ${ }^{31-33}$ we hypothesized that GSK3 may be involved in the impact of chronic alcohol intake on the consequences of AKI.

While many studies have shown that $\beta$-arrestins play an important role in regulating $\mathrm{G}$-protein-coupled receptor internalization, ${ }^{34} \beta$-arrestins can also interact with many signaling molecules and serve as scaffold proteins. ${ }^{35,36}$ Recent studies have shown that $\beta$-arrestin- 2 can form a complex with Akt and protein phosphatase 2 (PP2A) to mediate the dephosphorylation of Akt, which in turn results in GSK3 $\beta$ activation. $^{37}$ In addition, overexpression of $\beta$-arrestin-2 increases Akt-mediated activation of GSK3 $\beta$ in endometrial cancer cells. ${ }^{38}$ These studies suggested that Akt may mediate the effects of $\beta$-arrestin- 2 on the activation of GSK3 $\beta$ in the kidney. To test these hypotheses, we first examined the effects of alcohol pre-conditioning on the development of renal fibrosis following AKI in an animal model of bilateral renal
IRI. Furthermore, we examined the role of $\beta$-arrestin 2, Akt and GSK3 $\beta$ in the effect of chronic alcohol intake on the consequences of AKI. ${ }^{39}$

\section{MATERIALS AND METHODS}

\section{Animals}

$\beta$-Arrestin-2 knockout (KO) mice generated in the laboratory of R.J. Lefkowitz (Duke University Medical Center, Durham, NC, USA) were back-crossed to C57BL/6J mice for 10 generations. Wild-type (WT) or $\beta$-arrestin $\mathrm{KO}$ littermates from heterozygous breeding and descendants resulting from homozygous breeding of WT or $\beta$-arrestin KO mice after the initial back-crossing were used. All mice were individually housed in plastic mouse cages with free access to standard rodent chow (Teklad, Madison, WI, USA) and water except when an ethanol diet was introduced. The colony room was maintained at $\sim 22^{\circ} \mathrm{C}$ with a 12 -h light/dark cycle in which the lights were turned off at 0600 hours. In all experiments, 12-week-old male KO and WT control mice were used. The experimental timeline is shown in Figures la and b. All experiments were performed strictly in accordance with the National Institutes of Health Guide for the Care and Use of Laboratory Animals and were approved by the Animal Care and Use Committee of The Second Hospital of Hebei Medical University.

\section{Chronic alcohol administration}

The mice were randomly separated into two treatment groups. One group of mice received a dextrose-containing liquid diet, and a second group received a nutritionally complete liquid diet containing 4.5\% (v/v) ethanol (Abbott Laboratories, Abbott Park, IL, USA) in their home cages for 2 weeks. The diet used was a lactalbumin/ dextrose-based, nutritionally complete diet with concentrations of vitamins, minerals and other nutrients derived from ICN Research Diets. ${ }^{40-42}$ The dextrose calories in the normal diet were equated with the ethanol calories in the alcohol diet. Water was provided in a second bottle ad libitum throughout the treatment. The normal rodent chow was removed from the mouse cages during access to the diet. The diet was provided in drinking bottles fitted with ball-point sipper tubes to reduce spillage. The mice were habituated to the normal diet for the first 3 days and were then given access to the alcohol diet or normal diet for the next 2 weeks. On the day of 
bilateral ischemia-reperfusion (IR) surgery, the diet was removed, and the mice were continuously fed laboratory chow for the rest of the experiments. Blood was taken from the tail vein of each mouse to measure the blood alcohol concentration. Approximately $20 \mu \mathrm{l}$ of whole blood was collected into specialized capillary tubes, and the blood alcohol concentration was determined using the Analox alcohol analyzer (Analox Instruments, Lunenburg, MA, USA) at the end of the treatment. The average blood alcohol concentration was approximately $98 \pm 3.6 \mathrm{mg} \mathrm{dl}^{-1}$ at the end of the treatment.

\section{Bilateral IR surgery}

Bilateral IR was performed based on an established protocol as described previously ${ }^{43}$ on male Arrb2 $2^{-/-}$and WT C57BL/6J mice. Briefly, both renal pedicles were exposed by flank incisions and clamped using micro aneurysm clamps for 15 min under pentobarbital anesthesia $\left(60 \mathrm{mg} \mathrm{kg}^{-1}\right.$, i.p.). At the end of the ischemic period, the clamps were released for reperfusion. Sham groups of mice underwent surgery to expose the renal pedicles without clamping. To examine the role of GSK3 $\beta$ in the effects of chronic alcohol exposure on acute kidney injury, IR mice received a vehicle injection (1\% dimethylsulphoxide; $1 \mathrm{ml} \mathrm{kg}^{-1}$ ) or SB216763 (20 $\mathrm{mg} \mathrm{kg}^{-1}$; a potent inhibitor of GSK-3, Tocris Bioscience, Shanghai, China) 30 min before clamping.

\section{Measurement of creatinine and blood urea nitrogen}

Blood was collected from the tail vein, and the plasma was used to measure BUN and plasma creatinine using a QuantiChrom Urea Assay Kit from BioAssay Systems (Hayward, CA, USA) and a Creatinine Assay Kit (Abcam, Shanghai, China) respectively, following the manufacturer's instructions.

\section{Quantitative PCR}

Total RNA was extracted by Trizol (Invitrogen, Pleasanton, CA, USA) and reverse transcribed into complementary DNA using kits (Applied Biosystems, Waltham, MA, USA). The PCR with reverse transcription primers for GAPDH, collagen 1a1, TGF $\beta 1, \mathrm{CCN} 2$ and $\mathrm{CCN} 3$ are listed in Table 1. The PCR analyses were performed using a SYBR Greenbased system (Applied Biosystems), and the expression levels were normalized to GAPDH and expressed as relative levels to sham controls. Each gene was analyzed in triplicate. Calculations were performed using the comparative-CT method.

\section{Western blotting}

Kidney tissues were lysed in RIPA buffer and loaded onto SDS-polyacrylamide gel electrophoresis gels, transferred to

\section{Table 1 Primers used for RT-PCR}

\begin{tabular}{|c|c|}
\hline Gene name & Primers \\
\hline \multirow[t]{2}{*}{ Collagen-1a1 } & F AGACATGTTCAGCTTTGTGGAC \\
\hline & R GCAGCTGACTTCAGGGATG \\
\hline \multirow[t]{2}{*}{ TGF- $\beta 1$} & F TGAGTGGCTGTCTTTTTGACG \\
\hline & R AGCCCTGTATTCCGTCTCCT \\
\hline \multirow[t]{2}{*}{ CCN2 } & F CTCGGACTGTGATGCCTTAAT \\
\hline & R TGGATCCACACCTTGCATTTA \\
\hline \multirow[t]{2}{*}{ CCN3 } & F GAAGATTCCACGCCAATTCATC \\
\hline & R GATCTGCCGGTTTCTCTTAGTC \\
\hline \multirow{2}{*}{ GAPDH } & F TGCACCACCAACTGCTTAGC \\
\hline & R GGCATGGACTGTGGTCATGAG \\
\hline
\end{tabular}

Abbreviation: RT-PCR, PCR with reverse transcription. nitrocellulose membranes and blocked with 5\% milk in TBST. The membranes were probed with primary antibodies against Akt, pAkt (Thr308), GSK3 $\beta$, pGSK3 $\beta$ (Ser9), $\beta$-arrestin 2 (Cell Signaling Technology, Shanghai, China), collagen I, TGF $\beta 1$, CCN2, CCN3 (Abcam) and $\beta$-actin (Abcam), followed by washing with TBST and incubation with a horseradish peroxidase-conjugated secondary antibody (Sigma-Aldrich, Shanghai, China).

\section{Histology}

Renal tissues were fixed in $4 \%$ paraformaldehyde in $1 \times$ phosphatebuffered saline $(\mathrm{pH} 7.4)$ for $24 \mathrm{~h}$ at $4{ }^{\circ} \mathrm{C}$. After fixation, the tissue samples were routinely processed and embedded in paraffin wax (TissuePrep II, Fisher Scientific, Shanghai, China). Tissue sections of $5-\mu \mathrm{m}$ thickness were cut, placed on SuperfrostPlus slides (Fisher Scientific), de-paraffinized and rehydrated through a descending alcohol series. The tissue sections were routinely stained with Mayer's hematoxylin and Putt's eosin (H\&E). Masson's trichrome staining was also performed using a staining kit (Abcam) to visualize fibrotic tissue.

\section{Immunohistochemistry}

Paraffin sections were de-paraffinized, washed in phosphate-buffered saline containing $0.1 \%$ Tween 20 and then blocked in $10 \%$ normal goat serum. Primary antibodies against collagen I, $\alpha$-smooth muscle actin (SMA) and fibronectin were applied to the sections and incubated at $4{ }^{\circ} \mathrm{C}$ overnight. The sections were then washed in Tween 20-buffered saline and incubated with a biotinylated secondary antibody. After further washes with Tween 20-buffered saline, the sections were incubated with an avidin-biotinylated horseradish peroxidase complex. Finally, the sections were rewashed and developed by diaminobenzidine tetrahydrochloride (Sigma, Shanghai, China).

\section{Statistical analysis}

The data are expressed as the mean \pm s.d. All data analyses were performed using SPSS 20.0 statistical software. Multiple-group comparisons were analyzed by an analysis of variance (ANOVA) with a post hoc Tukey's test, and $P<0.05$ was considered statistically significant.

\section{RESULTS}

Chronic alcohol exposure potentiated bilateral IR-induced renal fibrosis and renal function impairment

We first examined the impact of chronic alcohol exposure on the consequences of bilateral IR-induced AKI. We found that 2 weeks of a $4.5 \%$ alcohol diet treatment did not induce renal fibrosis in sham mice compared with a normal diet treatment (Figures $2 \mathrm{a}-\mathrm{c}$ ). However, mice with IR-induced AKI developed renal fibrosis 14 days later compared with the sham controls (ANOVA, surgery main and interaction effects, $\mathrm{F}_{(1,28)}=28.77-34.19, \quad P<0.0001 ; \quad$ Tukey's test, $P<0.05$; Figures $2 \mathrm{a}-\mathrm{c})$. Furthermore, the chronic alcohol treatment enhanced IR-induced renal fibrosis in mice 14 days after surgery compared with the normal diet treatment (Tukey's test, $P<0.05$; Figures $2 \mathrm{a}-\mathrm{c}$ ). Dilated tubules and tubular atrophy were observed in the IR groups using H\&E staining, and the alcohol diet treatment group exhibited enhanced injury compared with the normal diet treatment group (Figure $2 \mathrm{~b}$ ). 
a

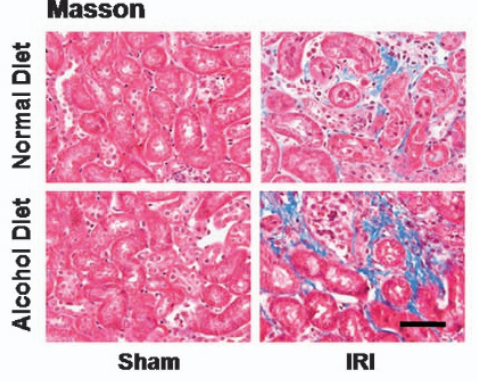

b

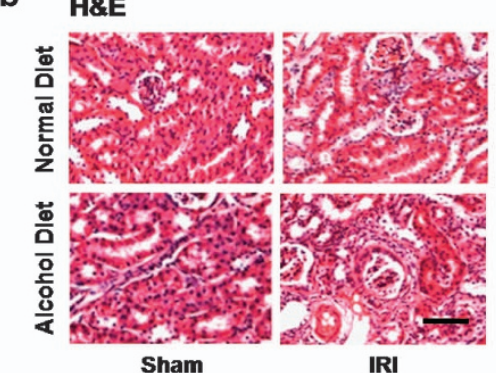

c

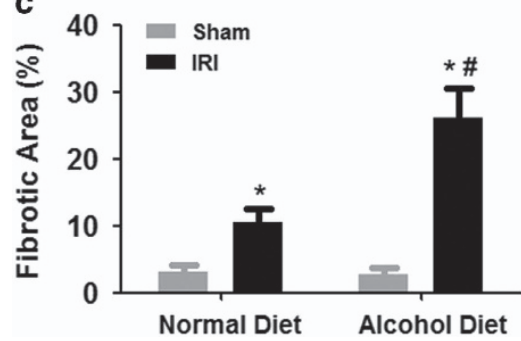

d
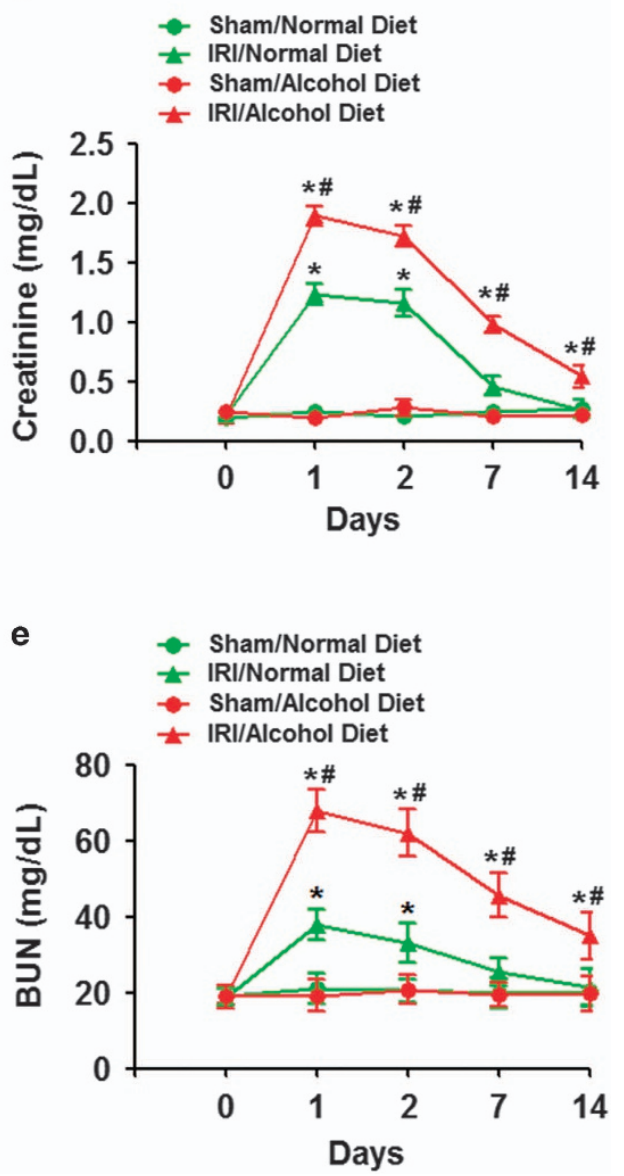

Figure 2 Effects of chronic alcohol exposure on bilateral ischemia-reperfusion (IR)-induced renal fibrosis and renal function impairment. (a) Representative images of Masson's trichrome staining. (b) Representative images of H\&E staining. (c) Fibrosis scores were assigned based on Masson's trichrome staining. (d) Plasma creatinine levels. (e) Blood urea nitrogen (BUN) levels. ${ }^{*} P<0.05$ compared to the sham group, ${ }^{\#}<0.05$ compared to the normal diet group; $n=8$ mice per group. Scale bar represents $50 \mu \mathrm{m}$. All tissue samples were collected at day 14 after IR.

Blood creatinine levels significantly increased in WT mice as early as $24 \mathrm{~h}$ after IR (ANOVA, surgery main and interaction effects, $\mathrm{F}_{(1-4,28-108)}=26.54-38.92, \quad P<0.0001$; Tukey's test, $P<0.05$; Figure 2d). However, the increased creatinine levels were exacerbated in mice with chronic alcohol exposure compared with the normal diet treatment group (ANOVA, treatment main effect, $\mathrm{F}_{(1,28)}=30.27, P<0.0001$; Tukey's test, $P<0.05$; Figure $2 \mathrm{~d}$ ). Furthermore, creatinine levels declined over 14 days after IR. Mice given the normal diet exhibited normal creatinine levels 14 days after IR (Figure 2d). However, the creatinine levels in mice with chronic alcohol exposure remained elevated 14 days after IR compared with the normal diet treatment group (Tukey's test, $P<0.05$; Figure $2 \mathrm{~d}$ ).

Similarly, BUN levels significantly increased in WT mice as early as $24 \mathrm{~h}$ after IR (ANOVA, surgery main and interaction effects, $\mathrm{F}_{(1-4,28-108)}=29.41-40.03, P<0.0001$; Tukey's test, $P<0.05$; Figure 2d). However, BUN levels were exacerbated in mice with chronic alcohol exposure compared with the normal diet treatment group (ANOVA, treatment main effect, $\mathrm{F}_{(1,28)}=33.18, P<0.0001$; Tukey's test, $P<0.05$; Figure 2d).
Furthermore, BUN levels declined over 14 days after IR. Mice given the normal diet treatment exhibited normal BUN levels 14 days after IR (Figure 2d). However, the BUN levels in mice with chronic alcohol exposure were still enhanced 14 days after IR compared with the normal diet treatment group (Tukey's test, $P<0.05$; Figure 2e).

Chronic alcohol exposure increased bilateral IR-induced extracellular matrix deposition and an increased myofibroblast population

Renal fibrosis is characterized by excessive extracellular matrix (ECM) remodeling. To determine the effect of chronic alcohol treatment on ECM deposition and the myofibroblast population, we examined the expression levels of collagen-1 and fibronectin, which are two major matrix components. We also determined the myofibroblast population in the kidneys by measuring $\alpha$-SMA expression levels, because active myofibroblasts are a major source of collagen and fibronectin. We found that 2 weeks of the $4.5 \%$ alcohol diet treatment did not induce excessive ECM deposition in sham mice compared 
a

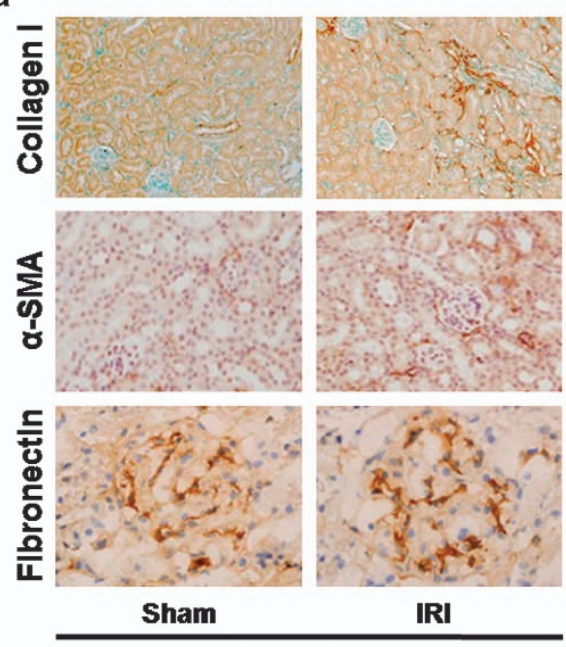

Normal Diet

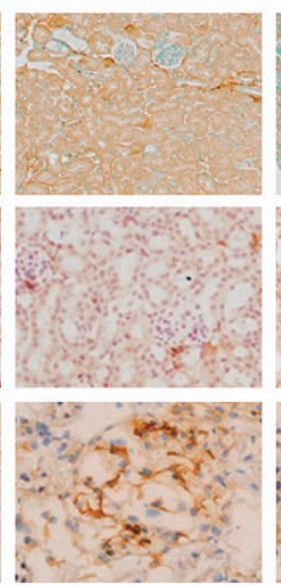

Sham
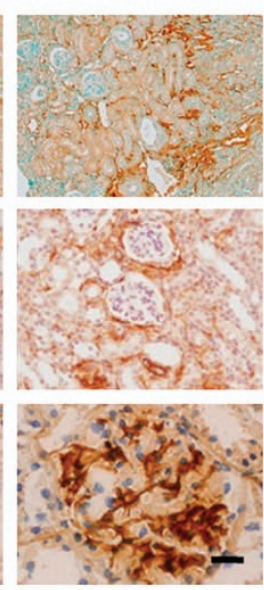

IRI
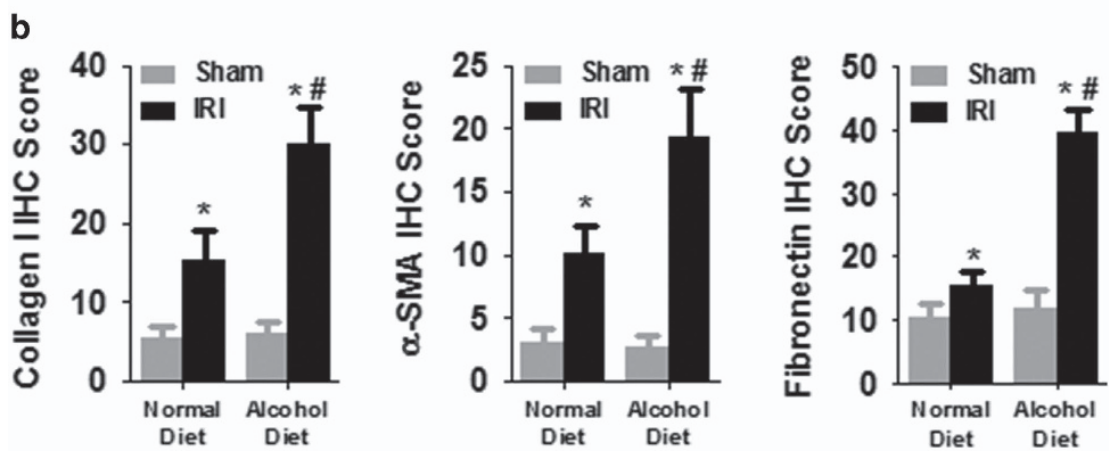

Figure 3 Effects of chronic alcohol exposure on bilateral ischemia-reperfusion (IR)-induced extracellular matrix deposition and myofibroblast population. (a) Representative images of immunostaining for fibronectin, collagen- 1 and $\alpha$-SMA in mouse renal tissues. (b) The area \% stain represents the ratio of the summed absolute areas of staining versus the total tissue. ${ }^{*} P<0.05$ compared to the sham group, ${ }^{\#} P<0.05$ compared to the normal diet group; $n=8$ mice per group. Scale bar represents $50 \mu \mathrm{m}$. All tissue samples were collected at day 14 after IR.

with the normal diet treatment (Figures $3 \mathrm{a}$ and $\mathrm{b}$ ). However, mice with IR-induced AKI exhibited enhanced collagen-1 and fibronectin deposition as well as $\alpha$-SMA expression at 14 days post IR compared with sham controls (ANOVA, surgery main and interaction effects, $\mathrm{F}_{(1,28)}=26.47-31.02, \quad P<0.0001$; Tukey's test, $P<0.05$; Figures $3 \mathrm{a}$ and $\mathrm{b}$ ). Furthermore, the chronic alcohol treatment enhanced IR-induced collagen-1 and fibronectin deposition as well as $\alpha$-SMA expression at 14 days post IR 14 compared with the normal diet treatment (Tukey's test, $P<0.05$; Figures $3 \mathrm{a}$ and $\mathrm{b}$ ).

Chronic alcohol exposure increased bilateral IR-induced expression of fibrosis-related genes in the kidneys

To further examine the effects of chronic alcohol exposure on renal fibrosis, we determined the mRNA and protein expression levels of several fibrosis-related genes, including Col I, TGF $\beta, C C N 2$ and CCN3. We found that 2 weeks of the $4.5 \%$ alcohol diet treatment did not induce the mRNA or protein expression of $\mathrm{Col} I, T G F \beta, C C N 2$ and $C C N 3$ compared with the normal diet treatment (Figures $4 \mathrm{a}-\mathrm{c}$ ). However, mice with IR-induced AKI exhibited enhanced mRNA and protein expression of Col I, TGF $\beta, C C N 2$ and $C C N 3$ at 14 days post
IR compared with the sham controls (ANOVA, surgery main and interaction effects, $\mathrm{F}_{(1,28)}=27.44-36.01, \quad P<0.0001$; Tukey's test, $P<0.05$; Figures $4 \mathrm{a}-\mathrm{c}$ ). Furthermore, the chronic alcohol treatment promoted IR-induced mRNA or protein expression of $\mathrm{Col} I, T G F \beta, C C N 2$ and $C C N 3$ at 14 days post IR compared with the normal diet treatment (Tukey's test, $P<0.05$; Figures $4 \mathrm{a}-\mathrm{c}$ ).

\section{Chronic alcohol exposure enhanced the expression of $\beta$-arrestin 2 and the activation of Akt and GSK3 $\beta$}

Given that $\beta$-arrestin 2 is critical in the regulation of GSK3 activation, which is involved in IR-induced renal fibrosis, we determined the effect of chronic alcohol treatment on the protein levels of $\beta$-arrestin 2, Akt, pAkt (Thr308), GSK3 $\beta$ and pGSK3 $\beta$ (Ser 9). We found that 2 weeks of the $4.5 \%$ alcohol diet treatment enhanced the protein expression of $\beta$-arrestin 2 in the kidneys compared with the normal diet treatment (Figures $5 \mathrm{a}$ and d). However, IR-induced AKI did not alter the protein expression of $\beta$-arrestin 2 at 14 days post IR compared with the sham controls (ANOVA, surgery main and interaction effects, $\mathrm{F}_{(1,28)}=29.11-33.19, P<0.0001$; Tukey's test, $P<0.05$; Figures $5 \mathrm{a}$ and $\mathrm{d}$ ). 
a
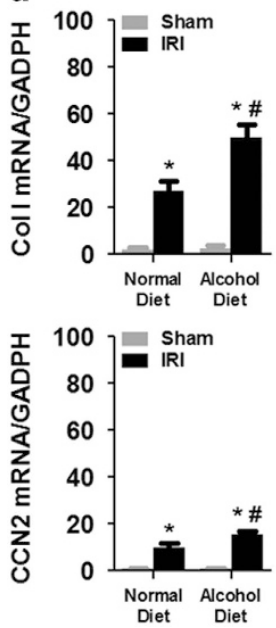
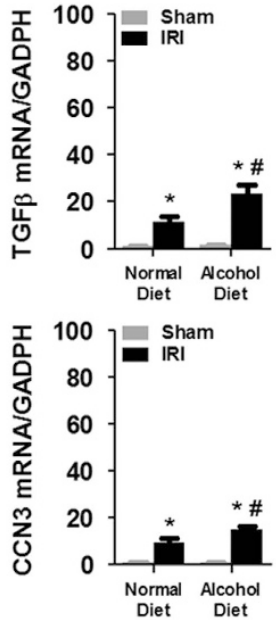

b
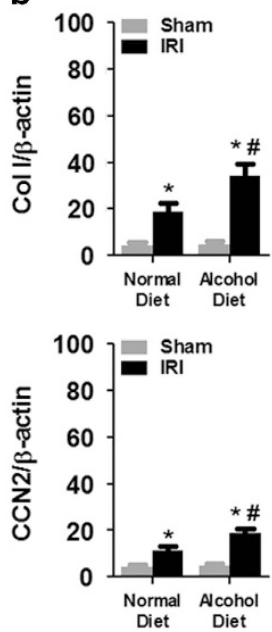
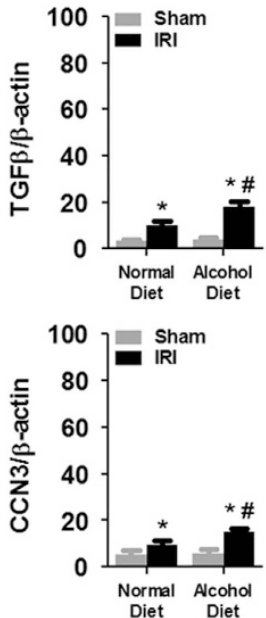

C

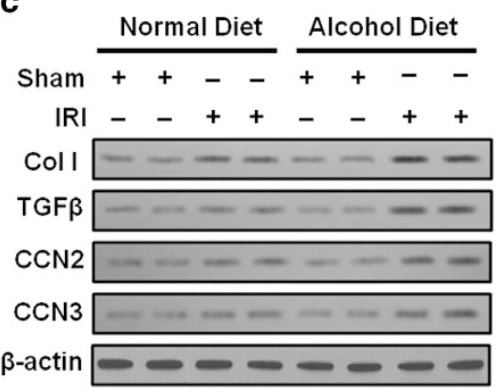

Figure 4 Chronic alcohol exposure increased the bilateral IR-induced expression of fibrosis-related genes in the kidney. (a) mRNA expression of Col I, TGF $\beta$, CCN2 and CCN3. The data were normalized to GAPDH. (b) Protein levels of Col I, TGF $\beta$, CCN2 and CCN3. (c) Representative western blots. ${ }^{*} P<0.05$ compared to the sham group, ${ }^{\#} P<0.05$ compared to the normal diet group; $n=8$ mice per group. All tissue samples were collected at day 14 after IR.

a

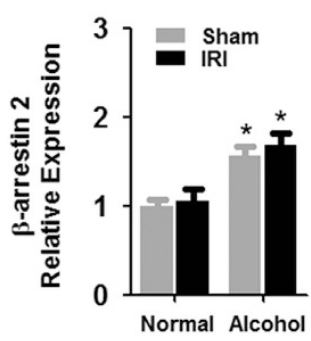

b

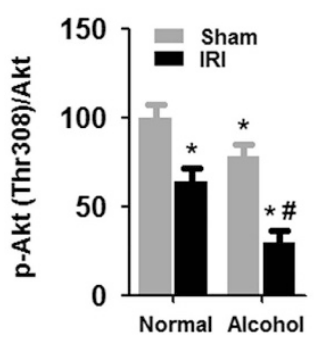

C

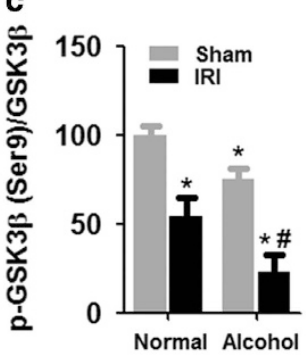

d d $\frac{\text { Normal Diet }}{++\ldots-} \frac{\text { Alcohol Diet }}{++--}$ IRI - $-++-\ldots+$

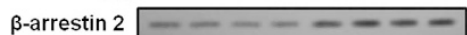
pAkt (Thr308) $-\ldots-\ldots$ Akt $-\cdots-\cdots$ $\operatorname{pGSK3\beta }$ (Ser9) $\ldots-\ldots$ GSK3 $-\cdots-\cdots$ $\beta$-actin $---\infty---$

Figure 5 Effects of chronic alcohol exposure on $\beta$-arrestin 2 expression and Akt and GSK3 $\beta$ activation. (a) Protein levels of $\beta$-arrestin 2. The data were normalized to $\beta$-actin and then to the sham/normal diet group. (b) Protein levels of Akt and p-Akt (Thr308). The p-Akt/Akt ratio was normalized to that of the sham/normal diet group. (c) Protein levels of GSK3 $\beta$ and p-GSK3 $\beta$ (Ser9). The p-GSK3 $\beta / G S K 3 \beta$ ratio was normalized to that of the sham/normal diet group. (d) Representative western blot. ${ }^{*} P<0.05$ compared to the sham/normal diet group, ${ }^{\#} P<0.05$ compared to the sham/alcohol diet group; $n=8$ mice per group. All tissue samples were collected at day 14 after IR.

In addition, chronic alcohol exposure did not alter the protein levels of Akt in the kidneys compared to the normal diet treatment (Figures $5 \mathrm{~b}$ and d). Moreover, IR-induced AKI did not alter the protein levels of Akt in the kidneys compared with sham controls (Figures $5 \mathrm{~b}$ and $\mathrm{d}$ ). However, 2 weeks of

the $4.5 \%$ alcohol diet treatment significantly decreased the protein levels of pAkt in the kidneys compared with the normal diet treatment (ANOVA, treatment main and interaction effects, $\mathrm{F}_{(1,28)}=36.47-46.33, P<0.0001$; Tukey's test, $P<0.05$; Figures $5 \mathrm{~b}$ and $\mathrm{d})$. Furthermore, IR-induced AKI reduced the protein levels of pAkt in the kidneys compared with sham controls (Tukey's test, $P<0.05$; Figures $5 \mathrm{~b}$ and d). Notably, IR-induced AKI reduced the protein levels of pAkt in the kidneys to a greater extent compared with the normal diet treatment (Tukey's test, $P<0.05$; Figures $5 \mathrm{~b}$ and $\mathrm{d}$ ).

Similarly, 2 weeks of the $4.5 \%$ alcohol diet treatment did not alter the protein levels of GSK3 $\beta$ in the kidneys compared with the normal diet treatment (Figures $5 \mathrm{c}$ and $\mathrm{d}$ ). In addition, IR-induced AKI did not alter the protein levels of GSK3 $\beta$ in the kidneys compared with sham controls (Figures $5 \mathrm{c}$ and $\mathrm{d}$ ). However, 2 weeks of the $4.5 \%$ alcohol diet treatment significantly decreased the protein levels of pGSK3 $\beta$ in the kidneys compared with the normal diet treatment (ANOVA, treatment main and interaction effects, $F_{(1,28)}=30.04-38.93$, $P<0.0001$; Tukey's test, $P<0.05$; Figures $5 \mathrm{c}$ and $\mathrm{d})$. Furthermore, IR-induced AKI reduced the protein levels of pGSK3 $\beta$ in the kidneys compared with sham controls (Tukey's test, $P<0.05$; Figures $5 \mathrm{c}$ and $\mathrm{d}$ ). Similar to the pAkt results, IR-induced AKI reduced the protein levels of pGSK3 $\beta$ in the kidneys to a greater extent compared with the normal diet treatment (Tukey's test, $P<0.05$; Figures $5 c$ and $d$ ).

GSK3 inhibition alleviated bilateral IR-induced renal fibrosis and renal function impairment

To determine whether GSK3 plays a critical role in mediating the effects of chronic alcohol treatment on IR-induced renal injury, we treated WT mice with SB216763 (20 $\mathrm{mg} \mathrm{kg}^{-1}$, IP), a GSK inhibitor, $30 \mathrm{~min}$ before IR and examined its effects on subsequent IR-induced renal fibrosis and renal function impairment. Replicating our previous findings, we found that 
a

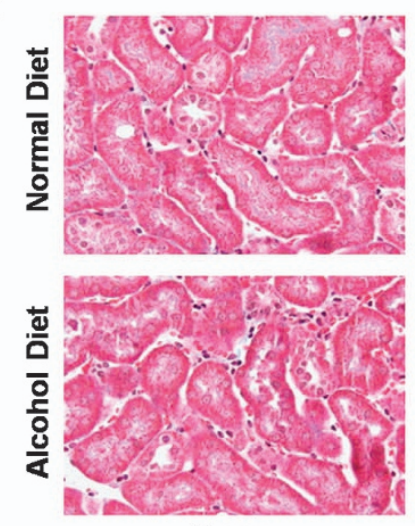

Sham

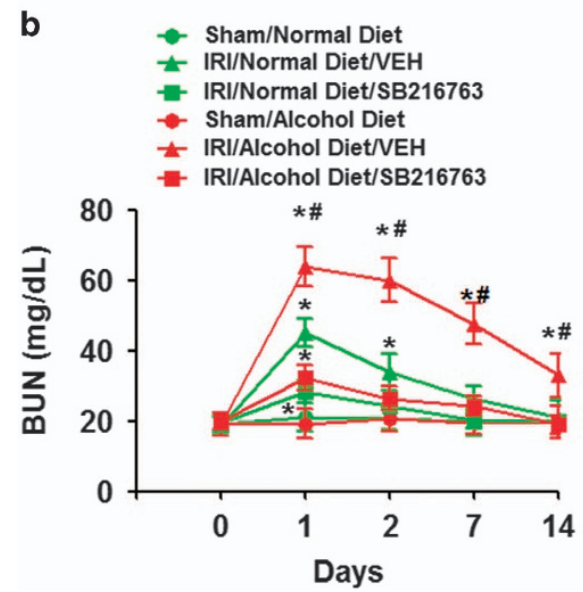

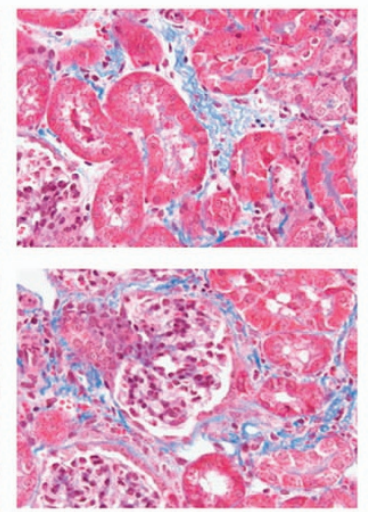

IRINehicle

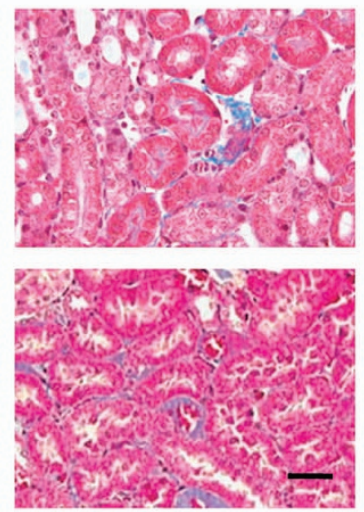

IRI/SB216763

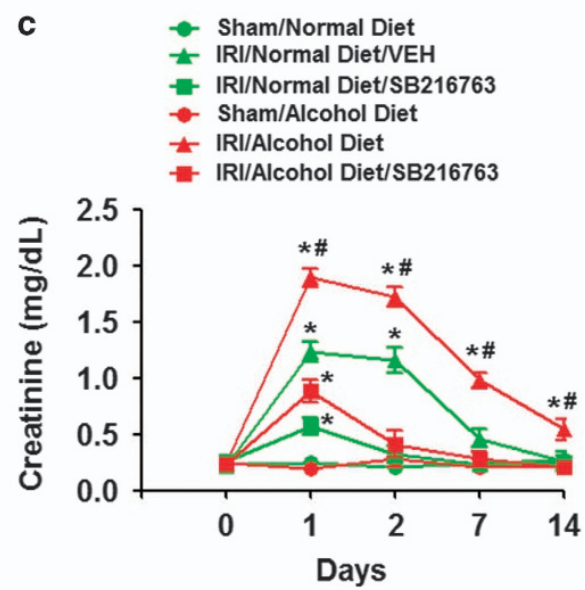

Figure 6 Effects of SB216763 on bilateral IR-induced renal fibrosis and renal function impairment. (a) Representative images of Masson's trichrome staining. (b) Blood urea nitrogen (BUN) levels. (c) Plasma creatinine levels. ${ }^{*} P<0.05$ compared to the sham group, ${ }^{\#} P<0.05$ compared to the normal diet group; $n=8$ mice per group. Scale bar represents $50 \mu \mathrm{m}$. All tissue samples were collected at day 14 after IR.

the chronic alcohol treatment enhanced IR-induced renal fibrosis in mice at 14 days post IR compared with the normal diet treatment (Figure 6a). However, mice pretreated with SB216763 (20 $\mathrm{mg} \mathrm{kg}^{-1}$, IP) exhibited much less renal fibrosis compared with vehicle-pretreated mice (ANOVA, treatment main and interaction effects, $\mathrm{F}_{(1,28)}=19.47-25.38, P<0.001$; Tukey's test, $P<0.05$; Figure $6 \mathrm{a}$ ).

Similarly, we found that the chronic alcohol treatment enhanced the IR-induced elevation of BUN and creatinine levels in mice compared with the normal diet treatment (Figures 6b and c). However, mice pretreated with SB216763 $\left(20 \mathrm{mg} \mathrm{kg}^{-1}\right.$, i.p.) exhibited much less enhancement of BUN and creatinine levels compared with vehicle-pretreated mice (ANOVA, treatment main and interaction effects, $\mathrm{F}_{(1,28)}=17.21-20.87, \quad P<0.01 ; \quad$ Tukey's test, $\quad P<0.05$; Figures $6 \mathrm{~b}$ and $\mathrm{c})$.

\section{Arrb2 ${ }^{-/-}$mice exhibited resistance to IR-induced renal} fibrosis and renal function impairment following chronic alcohol exposure

Given that we observed enhanced $\beta$-arrestin 2 levels in the kidneys after chronic alcohol exposure, we decided to determine whether $\beta$-arrestin 2 plays a critical role in mediating the effects of chronic alcohol treatment on IR-induced renal injury. We first found that sham-operated $A r r b 2^{-/-}$mice exhibited resistance to chronic alcohol treatment-induced GSK3 $\beta$ activation (that is, reduced pGSK3 $\beta$ (Ser9)/GSK3 $\beta$ ratio; Figure 7a), although IR induced a mild increase in GSK3 $\beta$ activation in chronic alcohol-treated $A r r b 2^{-/-}$mice, similar to that observed in normal diet-treated $\mathrm{Arrb2}^{-/-}$mice (Figure 7a). Similarly, the chronic alcohol treatment did not exaggerate renal fibrosis at 14 days post-IR in $A r r b 2^{-/-}$mice (Figure $7 \mathrm{~b}$ ). Furthermore, we confirmed that the chronic alcohol treatment did not alter the IR-induced protein expression of Col I, TGF,$C C N 2$ and CCN3 at 14 days post IR compared with the normal diet treatment (Figure 7c), although IR induced a mild increase in the protein expression of $\mathrm{Col} I$, $T G F \beta, C C N 2$ and CCN3 in chronic alcohol-treated Arrb2 $2^{-/-}$ mice, similar to that observed in normal diet-treated $A r r b 2^{-/-}$ mice (Figure 7c). Finally, we showed that $A r r b 2^{-/-}$mice exhibited resistance to IR-induced increases in BUN and creatinine levels, and the chronic alcohol treatment did not alter the IR-induced increases in BUN and creatinine levels compared with normal diet-treated Arrb2 ${ }^{-/-}$mice (Figure 7d). 
a

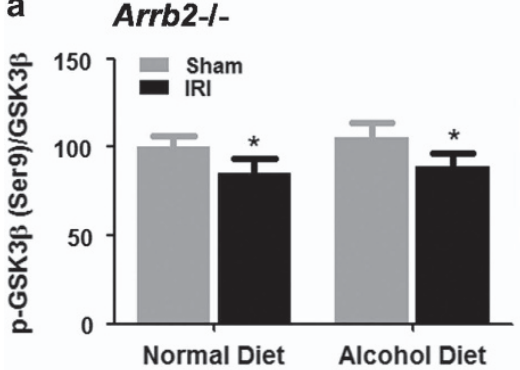

C
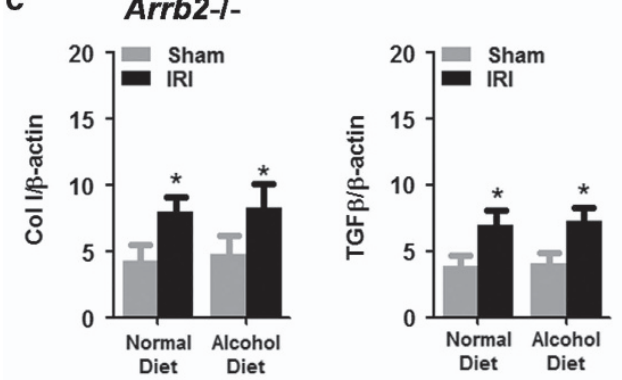

d

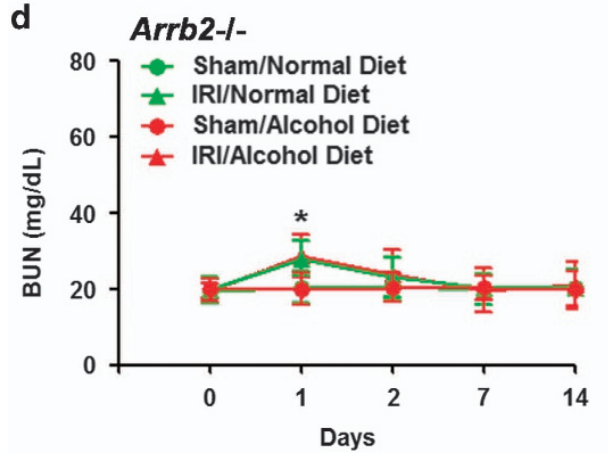

b
Arrb2-I-
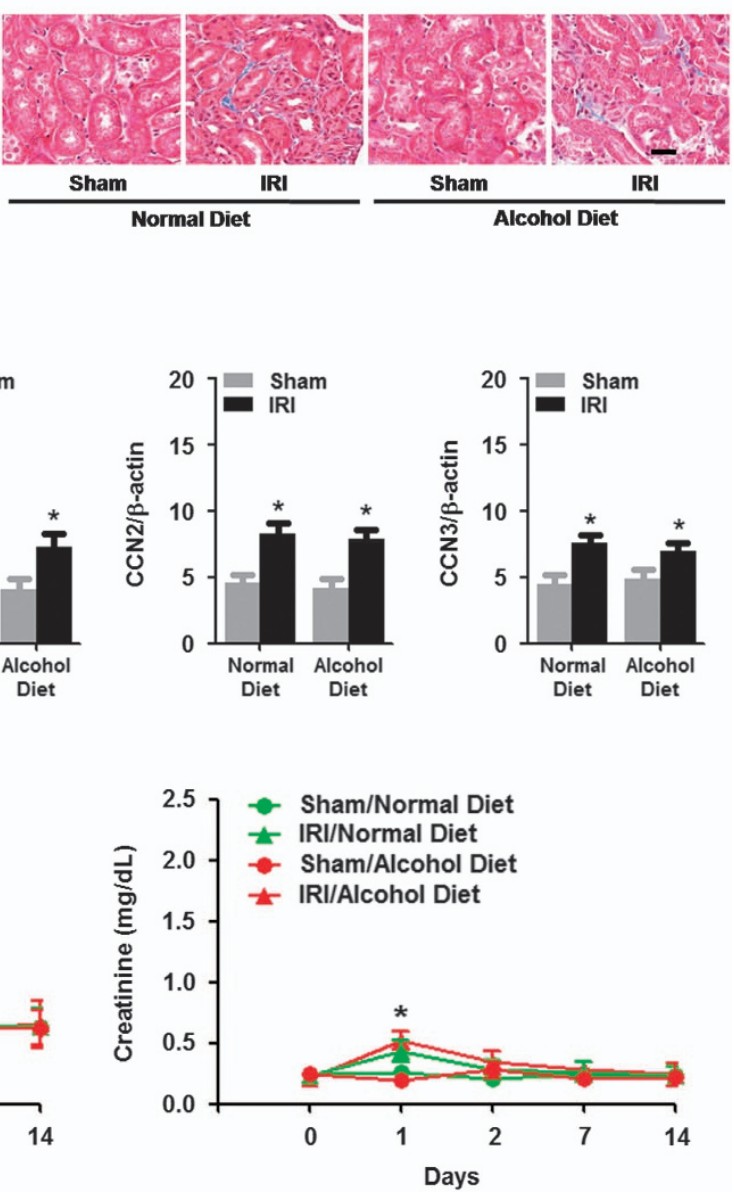

Figure 7 IR-induced renal fibrosis and renal function impairment following chronic alcohol exposure in Arrb2-1- mice. (a) Effects of IR-induced GSK3 $\beta$ activation in Arrb2-/- mice after chronic alcohol exposure. (b) Representative images of Masson's trichrome staining in Arrb2 $^{-1-}$ mice after chronic alcohol exposure. (c) Protein levels of Col I, TGF $\beta$, CCN2 and CCN3. (d) Blood urea nitrogen (BUN) and plasma creatinine levels. ${ }^{*} P<0.05$ compared to the sham group; $n=8$ mice per group. Scale bar represents $50 \mu \mathrm{m}$. All tissue samples were collected at day 14 after IR.

\section{DISCUSSION}

In this study, we examined the effects of chronic alcohol intake on the development of renal fibrosis following AKI in an animal model of bilateral renal IRI. We first found that chronic alcohol exposure exacerbated bilateral IR-induced renal fibrosis and renal function impairment. This phenomenon was associated with increased bilateral IR-induced extracellular matrix deposition and an increased myofibroblast population as well as increased bilateral IR-induced expression of fibrosisrelated genes in the kidneys. To explore the mechanisms underlying this phenomenon, we showed that chronic alcohol exposure enhanced $\beta$-arrestin 2 expression and Akt and GSK3 $\beta$ activation in the kidneys. Importantly, pharmacological GSK3 inhibition alleviated bilateral IR-induced renal fibrosis and renal function impairment. Furthermore, we demonstrated that $A r r b 2^{-1-}$ mice exhibited resistance to IR-induced renal fibrosis and renal function impairment following chronic alcohol exposure, and these effects were associated with attenuated GSK3 $\beta$ activation in the kidneys. Taken together, our results suggest that chronic alcohol exposure may exacerbate AKI via $\beta$-arrestin 2/Akt/GSK3 $\beta$-mediated signaling in the kidney. Numerous studies have demonstrated that acute alcohol pretreatment improves IR-induced injury and alleviates the subsequent dysfunction of multiple organs, including the heart, brain, liver, intestine and kidney. ${ }^{44-49}$ In fact, ethanol preconditioning experiments in animal models have shown that ethanol prevents post-ischemic adhesive interactions between leukocytes and endothelial cells, which can result in organ dysfunction and death. ${ }^{50,51}$ Furthermore, the anti-adhesive and anti-inflammatory effects of acute alcohol exposure are dependent on aldehyde dehydrogenase, which eliminates the toxic aldehydes produced by IR to prevent lipid peroxidation. ${ }^{48,50,52}$ However, studies have shown that acute alcohol exposure may have different effects than chronic alcohol exposure. For example, acute alcohol exposure has anti-inflammatory effects on lipopolysaccharide-induced 
inflammation in human monocytic cells in vitro and in vivo. ${ }^{53-55}$ In contrast, chronic alcohol exposure enhances inflammatory cytokine gene expression in humans and rodent models. ${ }^{56-58}$ Similarly, our results showed that chronic alcohol exposure may exacerbate AKI via activation of GSK3 $\beta$ mediated signaling in the kidney, which is likely mediated by the $\beta$-arrestin 2/Akt signaling pathway. Consistently, previous studies have shown that chronic ethanol intake can decrease the phosphorylation of Akt at Thr308 and increase phosphorylation at Ser473, which results in decreased GSK3 $\beta$ phosphorylation in rat liver tissues. ${ }^{31}$ In addition, ethanol can induce the dephosphorylation of GSK3 $\beta$ at Ser9 in the cerebral cortex of mice but has little effect on the expression of total GSK $3 \beta .^{32}$ Thus, our study adds to the literature by demonstrating for the first time that chronic alcohol exposure exacerbates IR-induced injury in the kidney.

It should be noted that withdrawal from chronic alcohol intake may also contribute to the development of renal fibrosis after AKI. In fact, studies have shown that the activity of the autonomic nervous system shifts to favor sympathetic activity during alcohol withdrawal. ${ }^{59,60}$ As a result, laboratory animals undergoing withdrawal experience changes in cardiovascular functions, such as elevated heart rate and blood pressure. It has been shown that renal sympathetic nerve activity is significantly augmented during renal ischemia. ${ }^{61,62}$ Renal denervation or administration of pentolinium, a ganglion blocking agent, before ischemia attenuates the ischemia/reperfusion-induced renal dysfunction and histological damage. ${ }^{61,63}$ Thus, it is likely that alcohol withdrawal-induced activation of renal sympathetic nerve activity also contributes to the subsequent deterioration of renal functions.

Consistent with previous studies showing that GSK3 $\beta$ is expressed in myofibroblasts in mouse kidneys, ${ }^{30}$ the present study also showed that GSK3 inhibition reduced the expression of $\alpha$-SMA, a marker of myofibroblast population, and inhibited the expression of several fibrosis-related genes, including TGF $\beta$, connective tissue growth factor (CCN2), and CCN3. As a critical mediator of fibrosis, TGF $\beta$ is well known to promote fibroblast activation, proliferation, migration and ECM synthesis. ${ }^{64,65}$ However, the role of GSK3 in regulating TGF $\beta$ signaling seems to be dependent on tissues or cells. Specifically, pharmacological GSK3 inhibition attenuates TGF $\beta 1$-mediated signaling and ECM accumulation in cultured renal glomerular mesenchymal cells and in lung, gingival, corneal and skin fibroblasts. ${ }^{66-70}$ In contrast, other studies have shown that GSK3 inhibition increases TGF $\beta 1$-induced $\beta$-catenin and Snail accumulation in a unilateral ureteral obstruction model and renal epithelial cells in vitro. ${ }^{71-74}$ Nonetheless, our results are consistent with a previous study showing that GSK3 inhibition significantly reduced the expression of TGF $\beta 1$ in a rodent IR model of AKI. ${ }^{30}$ In addition, the increased CCN2 and CCN3 expression in chronic alcohol-treated mice after renal IR may be due to enhanced GSK3 activation. We showed that inhibition of GSK3 reduced TGF- $\beta$, CCN2 and CCN3 expression. While we did not examine the role of TGF $\beta$ in the regulation of $\mathrm{CCN} 2$ and $\mathrm{CCN} 3$ expression in chronic alcohol-treated mice after renal IR, previous studies have shown that TGF $\beta 1$ strongly induces the expression of CCN2. ${ }^{75,76}$ Furthermore, GSK-3 $\beta$ activity is required for TGF $\beta_{1}$-mediated CCN2 expression in human gingival fibroblasts. ${ }^{66}$ Future studies will be important to examine the role of TGF $\beta$ in IR-induced injury in the kidney following chronic alcohol exposure.

One important finding in the present study is that $\beta$-arrestin 2 plays a critical role in the regulation of IR-induced injury in the kidney following chronic alcohol exposure. Increasing evidence reveals that $\beta$-arrestin 2 can modulate the activation of the serine/threonine kinase Akt. ${ }^{77,78}$ Activated Akt phosphorylates downstream GSK3 $\beta$ at serine 9, resulting in GSK3 $\beta$ inactivation. ${ }^{79,80}$ Our study showed that neither chronic alcohol exposure nor renal IR-induced AKI altered the expression of GSK3 $\beta$, but both reduced GSK3 $\beta$ phosphorylation at serine 9, indicating enhanced GSK3 $\beta$ activation. Similarly, previous studies have shown that the presence of $\beta$-arrestin 2 reduces Akt phosphorylation, which is associated with increased liver injury. ${ }^{81}$ While the mechanisms involved in the increased GSK3 $\beta$ activation after chronic alcohol exposure remain unclear, our study suggests that chronic alcohol exposure may enhance GSK3 $\beta$ activation by increasing $\beta$-arrestin 2 expression. Hence, additional studies will be needed to examine the specific role of Akt in mediating the regulation of GSK3 $\beta$ activation via $\beta$-arrestin 2 .

In conclusion, our study revealed that chronic alcohol exposure may potentiate AKI via $\beta$-arrestin $2 /$ GSK3 $\beta$-mediated signaling in the kidney. However, the pathogenesis of acute renal injury involves complex multi-cellular interactions within the heterogeneous renal tissue. Hence, future studies will be necessary to examine what might exacerbate acute kidney injury, which may allow the development of more specific and effective pharmacotherapies for the prevention of AKI.

\section{CONFLICT OF INTEREST}

The authors declare no conflict of interest.

1 Jones DR, Lee HT. Perioperative renal protection. Best Pract Res Clin Anaesthesiol 2008; 22: 193-208.

2 Li S, Fu S, Xiao Y, Xu G. Recent perioperative pharmacological prevention of acute kidney injury after cardiac surgery: a narrative review. Am J Cardiovasc Drugs 2017; 17: 17-25.

3 Picken M, Long J, Williamson GA, Polichnowski AJ. Progression of chronic kidney disease after acute kidney injury: role of self-perpetuating versus hemodynamic-induced fibrosis. Hypertension 2016; 68: 921-928.

4 Yerramilli M, Farace G, Quinn J. Kidney disease and the nexus of chronic kidney disease and acute kidney injury: the role of novel biomarkers as early and accurate diagnostics. Vet Clin North Am Small Anim Pract 2016; 46: 961-993.

5 Hsu RK, Hsu CY. The role of acute kidney injury in chronic kidney disease. Semin Nephrol 2016; 36: 283-292.

6 Jo SK, Rosner MH, Okusa MD. Pharmacologic treatment of acute kidney injury: why drugs haven't worked and what is on the horizon. Clin J Am Soc Nephrol 2007; 2: 356-365.

7 Cheungpasitporn W, Thongprayoon C, Kittanamongkolchai W, Brabec BA, O'Corragain OA, Edmonds PJ et al. High alcohol consumption and the risk of renal damage: a systematic review and meta-analysis. QJM 2015; 108 : 539-548. 
8 Arroyo V, Guevara M, Gines P. Hepatorenal syndrome in cirrhosis: pathogenesis and treatment. Gastroenterology 2002; 122: 1658-1676.

9 Wong F, Blendis L. New challenge of hepatorenal syndrome: prevention and treatment. Hepatology 2001; 34: 1242-1251.

10 Liamis GL, Milionis HJ, Rizos EC, Siamopoulos KC, Elisaf MS. Mechanisms of hyponatraemia in alcohol patients. Alcohol Alcohol 2000; 35: 612-616.

11 Elisaf MS, Siamopoulos KC. Mechanisms of hypophosphataemia in alcoholic patients. Int J Clin Pract 1997; 51: 501-503.

12 Ragland G. Electrolyte abnormalities in the alcoholic patient. Emerg Med Clin North Am 1990; 8: 761-773.

13 Wrenn KD, Slovis CM, Minion GE, Rutkowski R. The syndrome of alcoholic ketoacidosis. Am J Med 1991; 91: 119-128.

14 Skrypnyk NI, Harris RC, de Caestecker MP. Ischemia-reperfusion model of acute kidney injury and post injury fibrosis in mice. J Vis Exp 2013; 78: 50495.

15 Basile DP, Donohoe D, Roethe K, Osborn JL. Renal ischemic injury results in permanent damage to peritubular capillaries and influences long-term function. Am J Physiol Renal Physiol 2001; 281: F887-F899.

16 Ascon M, Ascon DB, Liu M, Cheadle C, Sarkar C, Racusen L et al. Renal ischemia-reperfusion leads to long term infiltration of activated and effector-memory T lymphocytes. Kidney Int 2009; 75: 526-535.

17 Stokman G, Leemans JC, Claessen N, Weening JJ, Florquin S. Hematopoietic stem cell mobilization therapy accelerates recovery of renal function independent of stem cell contribution. J Am Soc Nephrol 2005; 16 : 1684-1692.

18 Zager RA, Johnson AC, Becker K. Acute unilateral ischemic renal injury induces progressive renal inflammation, lipid accumulation, histone modification, and "end-stage" kidney disease. Am J Physiol Renal Physiol 2011; 301: F1334-F1345.

19 Zager RA, Johnson AC, Andress D, Becker K. Progressive endothelin-1 gene activation initiates chronic/end-stage renal disease following experimental ischemic/reperfusion injury. Kidney Int 2013; 84: 703-712.

$20 \mathrm{Kim} \mathrm{J}$, Padanilam BJ. Renal denervation prevents long-term sequelae of ischemic renal injury. Kidney Int 2015; 87: 350-358.

21 Singh AP, Junemann A, Muthuraman A, Jaggi AS, Singh N, Grover K et al. Animal models of acute renal failure. Pharmacol Rep 2012; 64: 31-44.

22 Bellomo R, Ronco C, Kellum JA, Mehta RL, Palevsky P. Acute renal failure - definition, outcome measures, animal models, fluid therapy and information technology needs: the Second International Consensus Conference of the Acute Dialysis Quality Initiative (ADQI) Group. Crit Care 2004; 8: R204-R212.

23 Bonventre JV, Yang L. Cellular pathophysiology of ischemic acute kidney injury. J Clin Invest 2011; 121: 4210-4221.

24 Venkatachalam MA, Griffin KA, Lan R, Geng H, Saikumar P, Bidani AK. Acute kidney injury: a springboard for progression in chronic kidney disease. Am J Physiol Renal Physiol 2010; 298: F1078-F1094.

25 Wang Z, Havasi A, Gall J, Bonegio R, Li Z, Mao H et al. GSK3beta promotes apoptosis after renal ischemic injury. J Am Soc Nephrol 2010; 21: 284-294.

26 Howard C, Tao S, Yang HC, Fogo AB, Woodgett JR, Harris RC et al. Specific deletion of glycogen synthase kinase-3beta in the renal proximal tubule protects against acute nephrotoxic injury in mice. Kidney Int 2012; 82: 1000-1009.

27 Bao H, Ge Y, Zhuang S, Dworkin LD, Liu Z, Gong R. Inhibition of glycogen synthase kinase-3beta prevents NSAID-induced acute kidney injury. Kidney Int 2012; 81: 662-673.

28 Plotnikov EY, Grebenchikov OA, Babenko VA, Pevzner IB, Zorova LD, Likhvantsev VV et al. Nephroprotective effect of GSK-3beta inhibition by lithium ions and delta-opioid receptor agonist dalargin on gentamicininduced nephrotoxicity. Toxicol Lett 2013; 220: 303-308.

29 Wang Y, Huang WC, Wang CY, Tsai CC, Chen CL, Chang YT et al. Inhibiting glycogen synthase kinase-3 reduces endotoxaemic acute renal failure by down-regulating inflammation and renal cell apoptosis. Br J Pharmacol 2009; 157: 1004-1013.

30 Singh SP, Tao S, Fields TA, Webb S, Harris RC, Rao R. Glycogen synthase kinase-3 inhibition attenuates fibroblast activation and development of fibrosis following renal ischemia-reperfusion in mice. Dis Model Mech 2015; 8: 931-940.

$31 \mathrm{He}$ L, Simmen FA, Mehendale HM, Ronis MJ, Badger TM. Chronic ethanol intake impairs insulin signaling in rats by disrupting Akt association with the cell membrane. Role of TRB3 in inhibition of Akt/protein kinase B activation. J Biol Chem 2006; 281: 11126-11134.

32 Liu Y, Chen G, Ma C, Bower KA, Xu M, Fan Z et al. Overexpression of glycogen synthase kinase 3 beta sensitizes neuronal cells to ethanol toxicity. J Neurosci Res 2009; 87: 2793-2802.
33 Luo J. GSK3beta in ethanol neurotoxicity. Mol Neurobiol 2009; 40: 108-121.

34 DeWire SM, Ahn S, Lefkowitz RJ, Shenoy SK. Beta-arrestins and cell signaling. Annu Rev Physiol 2007; 69: 483-510.

$35 \mathrm{Ma} \mathrm{L}$, Pei G. Beta-arrestin signaling and regulation of transcription. J Cell Sci 2007; 120(Pt 2): 213-218.

36 Lefkowitz RJ, Rajagopal K, Whalen EJ. New roles for beta-arrestins in cell signaling: not just for seven-transmembrane receptors. Mol Cell 2006; 24: 643-652.

37 Beaulieu JM, Marion S, Rodriguiz RM, Medvedev IO, Sotnikova TD, Ghisi V et al. A beta-arrestin 2 signaling complex mediates lithium action on behavior. Cell 2008; 132: 125-136.

38 Sun X, Zhang Y, Wang J, Wei L, Li H, Hanley G et al. Beta-arrestin 2 modulates resveratrol-induced apoptosis and regulation of Akt/GSK3ss pathways. Biochim Biophys Acta 2010; 1800: 912-918.

39 Costemale-Lacoste JF, Guilloux JP, Gaillard R. The role of GSK-3 in treatment-resistant depression and links with the pharmacological effects of lithium and ketamine: A review of the literature. Encephale 2016; 42: $156-164$.

40 Moy SS, Knapp DJ, Duncan GE, Breese GR. Enhanced ultrasonic vocalization and Fos protein expression following ethanol withdrawal: effects of flumazenil. Psychopharmacology 2000; 152: 208-215.

41 Moy SS, Knapp DJ, Criswell HE, Breese GR. Flumazenil blockade of anxiety following ethanol withdrawal in rats. Psychopharmacology 1997; 131: 354-360.

42 Sparta DR, Fee JR, Knapp DJ, Breese GR, Thiele TE. Elevated anxiety-like behavior following ethanol exposure in mutant mice lacking neuropeptide Y (NPY). Drug Alcohol Depend 2007; 90: 297-300.

43 Wei Q, Dong Z. Mouse model of ischemic acute kidney injury: technical notes and tricks. Am J Physiol Renal Physiol 2012; 303: F1487-F1494.

44 Miyamae M, Diamond I, Weiner MW, Camacho SA, Figueredo VM. Regular alcohol consumption mimics cardiac preconditioning by protecting against ischemia-reperfusion injury. Proc Natl Acad Sci USA 1997; 94: 3235-3239.

45 Collins MA, Neafsey EJ, Mukamal KJ, Gray MO, Parks DA, Das DK et al. Alcohol in moderation, cardioprotection, and neuroprotection: epidemiological considerations and mechanistic studies. Alcohol Clin Exp Res 2009; 33: 206-219.

46 Chen $\mathrm{CH}$, Budas GR, Churchill EN, Disatnik MH, Hurley TD, Mochly-Rosen D. Activation of aldehyde dehydrogenase-2 reduces ischemic damage to the heart. Science 2008; 321: 1493-1495.

47 Wang Q, Sun AY, Simonyi A, Kalogeris TJ, Miller DK, Sun GY et al. Ethanol preconditioning protects against ischemia/reperfusion-induced brain damage: role of NADPH oxidase-derived ROS. Free Radic Biol Med 2007; 43: 1048-1060.

48 Dayton C, Yamaguchi T, Kamada K, Carter P, Korthuis RJ. Antecedent ethanol ingestion prevents postischemic P-selectin expression in murine small intestine. Microcirculation 2004; 11: 709-718.

49 Yuan Q, Hong S, Han S, Zeng L, Liu F, Ding G et al. Preconditioning with physiological levels of ethanol protect kidney against ischemia/reperfusion injury by modulating oxidative stress. PLOS ONE 2011; 6: e25811.

50 Yamaguchi T, Dayton CB, Ross CR, Yoshikawa T, Gute DC, Korthuis RJ. Late preconditioning by ethanol is initiated via an oxidant-dependent signaling pathway. Free Radic Biol Med 2003; 34: 365-376.

51 Eltzschig HK, Collard CD. Vascular ischaemia and reperfusion injury. Br Med Bull 2004; 70: 71-86.

52 Yamaguchi T, Dayton C, Shigematsu T, Carter P, Yoshikawa T, Gute DC et al. Preconditioning with ethanol prevents postischemic leukocyteendothelial cell adhesive interactions. Am J Physiol Heart Circ Physiol 2002; 283: H1019-H1030.

53 Verma BK, Fogarasi M, Szabo G. Down-regulation of tumor necrosis factor alpha activity by acute ethanol treatment in human peripheral blood monocytes. J Clin Immunol 1993; 13: 8-22.

54 Szabo G, Chavan S, Mandrekar P, Catalano D. Acute alcohol consumption attenuates interleukin-8 (IL-8) and monocyte chemoattractant peptide-1 (MCP-1) induction in response to ex vivo stimulation. J Clin Immunol 1999; 19: $67-76$

55 Szabo G, Mandrekar P, Girouard L, Catalano D. Regulation of human monocyte functions by acute ethanol treatment: decreased tumor necrosis factor-alpha, interleukin-1 beta and elevated interleukin-10, and transforming growth factor-beta production. Alcohol Clin Exp Res 1996; 20: 900-907.

56 Zhang Z, Bagby GJ, Stoltz D, Oliver P, Schwarzenberger PO, Kolls JK. Prolonged ethanol treatment enhances lipopolysaccharide/phorbol 
myristate acetate-induced tumor necrosis factor-alpha production in human monocytic cells. Alcohol Clin Exp Res 2001; 25: 444-449.

57 Yin M, Wheeler MD, Kono H, Bradford BU, Gallucci RM, Luster MI et al. Essential role of tumor necrosis factor alpha in alcohol-induced liver injury in mice. Gastroenterology 1999; 117: 942-952.

58 Nagy LE. Recent insights into the role of the innate immune system in the development of alcoholic liver disease. Exp Biol Med 2003; 228: 882-890.

59 Hawley RJ, Nemeroff CB, Bissette G, Guidotti A, Rawlings R, Linnoila M. Neurochemical correlates of sympathetic activation during severe alcohol withdrawal. Alcohol Clin Exp Res 1994; 18: 1312-1316.

60 King AC, Parsons OA, Bernardy NC, Lovallo WR. Drinking history is related to persistent blood pressure dysregulation in postwithdrawal alcoholics. Alcohol Clin Exp Res 1994; 18: 1172-1176.

61 Fujii T, Kurata H, Takaoka M, Muraoka T, Fujisawa Y, Shokoji T et al. The role of renal sympathetic nervous system in the pathogenesis of ischemic acute renal failure. Eur J Pharmacol 2003; 481: 241-248.

62 Recordati GM, Moss NG, Waselkov L. Renal chemoreceptors in the rat. Circ Res 1978; 43: 534-543.

63 Ogawa Y, Masuzaki H, Ebihara K, Shintani M, Aizawa-Abe M, Miyanaga F et al. Pathophysiogical role of leptin in lifestyle-related diseases. Studies with transgenic skinny mice overexpressing leptin. J Diabetes Complications 2002; 16: 119-122.

64 Kramann R, DiRocco DP, Humphreys BD. Understanding the origin, activation and regulation of matrix-producing myofibroblasts for treatment of fibrotic disease. J Pathol 2013; 231: 273-289.

65 Zarjou A, Agarwal A. Heme oxygenase-1 as a target for TGF-beta in kidney disease. Semin Nephrol 2012; 32: 277-286.

66 Bahammam M, Black SA Jr, Sume SS, Assaggaf MA, Faibish M, Trackman PC. Requirement for active glycogen synthase kinase-3beta in TGF-betal upregulation of connective tissue growth factor (CCN2/CTGF) levels in human gingival fibroblasts. Am J Physiol Cell Physiol 2013; 305: C581-C590.

67 Ho C, Lee PH, Hsu YC, Wang FS, Huang YT, Lin CL. Sustained Wnt/beta-catenin signaling rescues high glucose induction of transforming growth factor-betal-mediated renal fibrosis. Am J Med Sci 2012; 344: 374-382.

68 Liu J, Wang Y, Pan Q, Su Y, Zhang Z, Han J et al. Wnt/beta-catenin pathway forms a negative feedback loop during TGF-betal induced human normal skin fibroblast-to-myofibroblast transition. J Dermatol Sci 2012; 65: 38-49.

69 Choi SI, Kim BY, Dadakhujaev S, Jester JV, Ryu H, Kim TI et al. Inhibition of TGFBIp expression by lithium: implications for TGFBI-linked corneal dystrophy therapy. Invest Ophthalmol Vis Sci 2011; 52: 3293-3300.

70 Zhang M, Lee CH, Luo DD, Krupa A, Fraser D, Phillips A. Polarity of response to transforming growth factor-beta1 in proximal tubular epithelial cells is regulated by beta-catenin. J Biol Chem 2007; 282: 28639-28647.
71 Lan A, Qi Y, Du J. Akt2 mediates TGF-beta1-induced epithelial to mesenchymal transition by deactivating GSK3beta/snail signaling pathway in renal tubular epithelial cells. Cell Physiol Biochem 2014; 34: 368-382.

72 Noh H, Kim HJ, Yu MR, Kim WY, Kim J, Ryu JH et al. Heat shock protein 90 inhibitor attenuates renal fibrosis through degradation of transforming growth factor-beta type II receptor. Lab Invest 2012; 92: 1583-1596.

73 Yoshino J, Monkawa T, Tsuji M, Inukai M, Itoh H, Hayashi M. Snail1 is involved in the renal epithelial-mesenchymal transition. Biochem Biophys Res Commun 2007; 362: 63-68.

74 Zhou BP, Deng J, Xia W, Xu J, Li YM, Gunduz M et al. Dual regulation of Snail by GSK-3beta-mediated phosphorylation in control of epithelialmesenchymal transition. Nat Cell Biol 2004; 6: 931-940.

75 Holmes A, Abraham DJ, Sa S, Shiwen X, Black CM, Leask A. CTGF and SMADs, maintenance of scleroderma phenotype is independent of SMAD signaling. J Biol Chem 2001; 276: 10594-10601.

76 Mori T, Kawara S, Shinozaki M, Hayashi N, Kakinuma T, Igarashi A et al. Role and interaction of connective tissue growth factor with transforming growth factor-beta in persistent fibrosis: a mouse fibrosis model. J Cell Physiol 1999; 181: 153-159.

77 Povsic TJ, Kohout TA, Lefkowitz RJ. Beta-arrestin1 mediates insulin-like growth factor 1 (IGF-1) activation of phosphatidylinositol 3-kinase (PI3K) and anti-apoptosis. J Biol Chem 2003; 278: 51334-51339.

78 Beaulieu JM, Sotnikova TD, Marion S, Lefkowitz RJ, Gainetdinov RR, Caron MG. An Akt/beta-arrestin 2/PP2A signaling complex mediates dopaminergic neurotransmission and behavior. Cell 2005; 122: 261-273.

79 Jope RS, Johnson GV. The glamour and gloom of glycogen synthase kinase3. Trends Biochem Sci 2004; 29: 95-102.

80 Martin M, Rehani K, Jope RS, Michalek SM. Toll-like receptor-mediated cytokine production is differentially regulated by glycogen synthase kinase 3. Nat Immunol 2005; 6: 777-784.

81 Yin D, Yang X, Li H, Fan H, Zhang X, Feng Y et al. Beta-arrestin 2 promotes hepatocyte apoptosis by inhibiting Akt protein. J Biol Chem 2016; 291: 605-612.

This work is licensed under a Creative Commons Attribution 4.0 International License. The images or other third party material in this article are included in the article's Creative Commons license, unless indicated otherwise in the credit line; if the material is not included under the Creative Commons license, users will need to obtain permission from the license holder to reproduce the material. To view a copy of this license, visit http:// creativecommons.org/licenses/by/4.0/ 